Vol. 7, No. 3, 2019, pp. 97-103

DOI: https://doi.org/10.29210/132700

Contents lists available at Jurnal IICET

Jurnal Konseling dan Pendidikan

ISSN: 2337-6740 (Print) ISSN: 2337-6880 (Electronic)

Journal homepage: http://jurnal.konselingindonesia.com

\title{
Online game addiction in addolescent: What should school counselor do?
}

\author{
Eryzal Novrialdy $^{1}$, Rozi Atyarizal $^{2}$ \\ ${ }^{1}$ Universitas Negeri Padang, Indonesia \\ ${ }^{2}$ SMP Negeri 21 Kerinci, Indonesia
}

\begin{tabular}{|c|c|}
\hline Article Info & ABSTRACT \\
\hline Article history: & Online game addiction in adolescents has become one of the problems that get \\
\hline Received Aug $13^{\text {th }}, 2019$ & a lot of public attention. Increasingly developing of technology, easy access \\
\hline Revised Oct $15^{\text {th }}, 2019$ & and lack of comprehension of adolescents towards the dangers of online game \\
\hline Accepted Dec $30^{\text {th }}, 2019$ & addiction are some of the factors that easily make adolescent become addicted \\
\hline & $\begin{array}{l}\text { to online games. Online game addiction is a play activity that is carried out } \\
\text { excessively and interferes with daily life. Online game addiction that occur in }\end{array}$ \\
\hline Keyword: & adolescents can have an impact on various aspects of life, such as health \\
\hline Prevention & aspects, psychological aspects, academic aspects, social aspects and financial \\
\hline Online game & aspects. This problem must be prevented, one of them is by school counselor. \\
\hline Addiction & Various prevention efforts can be carried out by school counselor, include: \\
\hline School counselor & minars, socialization and online game addiction hazard modules. \\
\hline
\end{tabular}

Corresponding Author:

Eryzal Novrialdy,

Email: erynvrld@gmail.com

\section{Pendahuluan}

Perkembangan teknologi pada era digital ini tidak dapat dipungkiri sangat pesat adanya. Salah satu produk perkembangan teknologi yang saat ini digemari remaja adalah game online. Kegemaran remaja bermain game online ternyata malah menghadirkan permasalahan yaitu kecanduan game online. Permasalahan kecanduan game online mesti dipandang sebagai masalah yang timbul dari ketidakmampuan menyikapi perkembangan teknologi. Bahkan Anggarani (2015) menyebut kecanduan game online sebagai psikopatologi budaya modern. Pendapat ini dapat dibenarkan karena memang game online merupakan produk dari budaya modern, yang semestinya dimanfaatkan untuk hiburan sewajarnya tetapi malah dimainkan secara berlebihan serta digunakan sebagai tempat untuk melarikan diri dari realitas kehidupan sehingga yang terjadi adalah kecanduan game online (Hussain \& Griffiths, 2009).

Kecanduan game online pada remaja telah menjadi salah satu masalah yang banyak mendapat perhatian masyarakat. Di Korea Selatan bahkan pemerintah setempat telah membuat program khusus untuk penanganan kecanduan game online (Koo et al., 2011). Terlepas dari banyaknya aspek bermanfaat dari penggunaan game online, penggunaan game online yang bermasalah telah meningkat dan telah terkait dengan berbagai aspek kehidupan. Kecanduan game online dapat memberikan dampak negatif atau bahaya bagi remaja yang mengalaminya. Bahaya yang akan muncul akibat kecanduan game online antara lain acuh tak acuh pada kegiatan lain, memunculkan rasa tak tenang saat tidak bermain game (Jannah et al., 2015), kehilangan kontrol atas waktu, menurunnya prestasi akademik, relasi sosial, finansial dan kesehatan (Ghuman \& Griffiths, 2012). Hal ini tentu akan mengganggu tumbuh dan kembang remaja. Oleh karena itu, diperlukan upaya pencegahan terhadap permasalahan kecanduan game online. Mengingat dampak negatif dan juga perkembangan era digital yang tak bisa dipungkiri sangat pesat adanya. 
Salah satu pendidik yang memiliki tugas untuk mencegah terjadinya perilaku buruk siswa ialah guru Bimbingan dan Konseling (BK). Dalam era sekarang peran guru BK harus lebih proaktif dalam pencegahan dan intervensi ke semua siswa (Romano \& Hage, 2000; Romano \& Netland, 2008; Stone \& Dahir, 2015). Pelayanan BK berupa pencegahan kecanduan game online merupakan cara yang lebih efektif untuk remaja (Park \& Chen, 2007). Sejauh ini belum ada penanganan khusus tentang pencegahan kecanduan game online (Syahran, 2015). Sebaliknya, banyak penelitian yang telah difokuskan pada remaja yang terkena kecanduan game online (Dong \& Potenza, 2014; Griffiths, Kuss, \& Pontes, 2016; King et al., 2017; Pallesen, Lorvik, $\mathrm{Bu}, \&$ Molde, 2015). Terlebih lagi di Indonesia, masih terasa sekali stigma negatif terhadap pelayanan BK (Sanderi, Marjohan, \& Sukmawati, 2013; Wangid, 2010). Hal ini tidak lepas dari intensitas guru BK yang lebih sering melakukan tindakan kuratif daripada tindakan preventif terhadap perilaku bermasalah siswa (Zamroni \& Rahardjo, 2015). Dalam hal ini perlu dilakukan reorientasi pelayanan BK dengan cara mengubah pendekatan yang selama ini berlangsung di sekolah. Dengan lebih fokus terhadap upaya pencegahan, diharapkan persepsi negatif ini akan berubah di masa yang akan datang. Untuk itu, dalam artikel ini penulis mencoba memberikan alternatif dari pencegahan kecanduan game online.

\section{Pembahasan}

\section{Remaja dan Kecanduan Game Online}

Kecanduan game online merupakan salah satu jenis bentuk kecanduan dari teknologi internet atau yang lebih dikenal dengan internet addictive disorder (Young, 2011). Kecanduan game online adalah hilangnya kendali terhadap game online yang mengarah pada bahaya (van Rooij et al., 2011). Selain itu, American Psychiatric Association (2013) menjelaskan bahwa kecanduan game online adalah pengguanan game online secara terus-menerus dan berulang yang sering mengarah pada terganggunya kehidupan sehari-hari. Berdasarkan penjelasan tersebut, dapat disimpulkan kecanduan game online adalah hilangnya kontrol atau kendali terhadap penggunaan berlebihan permainan yang terhubung dengan internet sehingga menyebabkan kegiatan sehari-hari terganggu.

Pada dasarnya bermain game baik, asal tidak berlebihan. Menurut Han, Hwang, \& Renshaw (2010) bermain game online dapat dikatakan bermasalah apabila dimainkan melebihi 4 jam setiap hari. Griffiths, Davies, \& Chappell (2004) mengungkapkan bahwa pemain usia remaja menghabiskan lebih banyak waktu dan memiliki keterikatan yang lebih kuat dengan game online dibanding pemain usia dewasa. Fenomena yang terjadi saat ini menunjukkan adanya remaja yang kecanduan game online. Berdasarkan penelitian Jap, Tiatri, Jaya, \& Suteja (2013) terungkap 10,15\% remaja di Indonesia mengalami kecanduan game online, Amerika Serikat 8,5\% (Gentile, 2009), Singapura 8,7\% (Choo et al., 2010) dan China 10,8\% (Lam \& Peng, 2010). Fenomena kecanduan game online ini semakin meluas dan semakin memprihatinkan, terutama karena banyaknya remaja yang menjadi pecandu game online. Hal ini tentu akan berdampak buruk bagi perkembangan remaja.

Kecanduan game online pada remaja dapat berdampak pada tugas-tugas perkembangannya. Jika dilihat pada realitanya banyak sekali remaja yang terganggu tugas perkembangannya akibat kecanduan game online. Tugas perkembangan tersebut menurut Hurlock (2010), antara lain:

\section{Menjalin hubungan baru dan yang lebih matang dengan teman sebaya}

Secara psikologis masa remaja merupakan masa untuk berintegrasi dengan orang di sekitarnya. Pada periode ini, remaja tidak hanya dituntut untuk bersosialisasi dengan keluarga, namun juga dengan masyarakat sehingga remaja dapat berbaur dan menyesuaikan diri dengan norma yang berlaku di masyarakat (Prayitno, 2006).

Game online merupakan ruang sosial atau dunia sosial baru tempat para pemainnya menghabiskan waktu dan berinteraksi dengan orang lain serta membentuk pertemanan (Taylor, 2006). Hal ini merupakan salah satu daya tarik game online. Namun, dunia remaja adalah dunia nyata bukan dunia maya yang dalam hal ini adalah game online. Remaja membutuhkan interaksi sosial yang nyata untuk membentuk huhungan sosial yang baik.

Remaja banyak menggunakan smartphone untuk bermain game online. Intensitas yang tinggi dalam bermain game online di smartphone dapat menyebabkan perilaku phubbing (Hanika, 2015). Kata phubbing berasal dari dua kata yaitu phone dan snubbing, yang berarti perilaku menyibukkan diri dengan smartphone selama percakapan dengan orang lain (Karadağ et al., 2015). Perilaku phubbing dapat menyebabkan remaja 
kekurangan interaksi, dapat menghilangkan kemampuan untuk membangun hubungan dan komunikasi dengan baik (Afdal et al., 2019)

Hasil penelitian Grizzard, Tamborini, Lewis, Wang, \& Prabhu (2014) menunjukkan hubungan antara kinerja perilaku anti sosial dengan videogame. Remaja yang kecanduan game online akan kesulitan untuk menjalin hubungan sosial baik dengan teman sebaya ataupun masyarakat lainnya. Hal ini disebabkan waktu yang dihabiskan remaja untuk bermain game online terlalu banyak sehingga kesempatan menjalin relasi menjadi berkurang. Bermain game online juga bisa saja dilakukan karena untuk lari dari permasalahan namun jelas bukan suatu pilihan yang bijak karena suatu masalah tidak akan selesai jika terus lari dari masalah tersebut tanpa mau menyelesaikannya.

\section{Mencapai kemandirian emosional}

Pencapaian kemandirian emosional berkaitan dengan regulasi emosi. Regulasi emosi akan menjadi benteng dalam pengendalian emosi pada situasi tertentu, termasuk dalam situasi bermain game online. Terkadang dalam situasi bermain game online, remaja seringkali mengeluarkan kata-kata kasar yang tidak mencerminkan adanya regulasi diri (Petrides \& Furnham, 2000). Oleh karena itu, remaja harus dapat mengatur dirinya sebelum memberikan respon dalam peristiwa tertentu.

Kecanduan game online erat kaitannya dengan depresi (Lemola et al., 2011). Dari hasi penelitiannya menunjukkan bahwa jumlah waktu yang dihabiskan untuk game terkait dengan tingkat depresi yang lebih tinggi. Selain itu, kecanduan game online juga terkait dengan kecemasan (Cheever et al., 2014). Penggunaan game online secara berkepanjangan akan mengakibatkan remaja cemas dan gelisah ketika tidak bermain game online. Dapat dipahami bahwa remaja yang mengalami kecanduan game online secara emosionalnya tidak stabil dan belum mampu memberi respon positif terhadap permainannya di game online. Selain itu, juga dapat disimpulkan bahwa remaja belum mencapai kemandirian emosional apabila mengalami kecanduan game online.

\section{Mencapai perilaku sosial bertanggungjawab}

Pecandu game online memiliki bias dalam cara menafsirkan dan memproses informasi terkait game (Zhou et al., 2012). Bias ini berasal dari aktivitas berulang bermain game online (Brand et al., 2016). Kondisi ini membuat remaja terkena dampak negatif dari kecanduan game online, yang membuat lepasnya tanggungjawab terhadap kegiatan sehari-hari lainnya.

\section{Mempersiapkan karier ekonomi}

Game online selain sebagai bentuk hiburan juga dapat menghasilkan uang. Dapat dibuktikan dengan transaksi jual beli item dalam game online dan penjualan akun (Ducheneaut \& Moore, 2004). Hal ini tentu membuat game online menjadi ladang mencari uang, apalagi dengan berkembangnya eSport. Hamari \& Sjöblom (2017) mendefinisikan eSports sebagai bentuk olahraga yang difasilitasi oleh sistem elektronik. Selama beberapa tahun terakhir, eSports dan streaming game menjadi sangat cepat berkembang. Perkembangan eSport membuat terciptanya ruang baru terhadap cita-cita masa depan remaja.

Baru-baru ini, bermain game online telah menjadi pekerjaan untuk sebagian kecil pemain di dunia game profesional (Griffiths, 2017). Esport menjadi area baru dalam budaya game dan mulai menjadi salah satu bagian paling penting dan populer dari komunitas game, terutama dikalangan remaja. Terlebih dengan berkembangnya jenis baru dari game online yang dapat dimainkan di smartphone yaitu MOBA (Multiplayer Online Battle Arena). Hal ini tentu mendukung perkembangan eSport.

Selain menimbulkan dampak positif, eSport juga menimbulkan dampak negatif. Masalah kecanduan game online muncul dengan semakin populernya eSports. Hal ini terkait dengan usaha untuk pencapaian menjadi pemain eSport yang terkadang mengabaikan banyak hal. Sesuai dengan pendapat Weiss (2011) yang menyatakan bahwa kompetisi, tantangan dan pelarian terkait positif dengan eSports. Selain itu, game yang kompetitif dapat menghasilkan tingkat agresi yang lebih tinggi dibandingkan dengan game yang tidak kompetitif (Hughes \& Louw, 2013). Berdasarkan penjelasan tersebut, dapat disimpulkan bahwa remaja perlu mendapatkan pemahaman yang utuh tentang eSport sebagai pilihan pekerjaan yang baru agar remaja dapat memahami tentang keuntungan dan konsekuensi dari eSport serta mencegah perilaku bermasalah terhadap permainan game online.

\section{Upaya Pencegahan Kecanduan Game Online pada Remaja}

Saat ini hampir setiap remaja memiliki akses yang sangat mudah terhadap berbagai perkembangan teknologi, terutama pada game online. Selain itu, prevalensi kecanduan game online lebih tinggi pada 
remaja (Rehbein et al., 2015). Untuk itu kecanduan game online pada remaja perlu mendapat upaya pencegahan.

Pencegahan adalah istilah yang mencakup beragam intervensi yang bertujuan menghalangi dan menghindari kondisi yang berisiko bermasalah (O'Connell et al., 2009). Pencegahan kecanduan game online dapat dilakukan keluarga, sekolah dan masyarakat (O'Connell et al., 2009; Rutter et al., 2017). Xu, Turel, \& Yuan (2012) mengungkapkan 6 faktor pencegahan kecanduan game online, yaitu attention switching, dissuasion, education, parental monitoring dan perceived cost.

Salah satu faktor pencegahan kecanduan game online yang telah disebutkan, yaitu education atau pendidikan. Pendidikan dapat ditujukan untuk membangun kognisi yang baik sehingga individu memiliki pemahaman tentang bahaya kecanduan game online. Selain itu, pendidikan juga dapat mendorong pemikirian rasional sehingga mengurangi penggunaan berlebihan yang pada akhirnya dapat mencegah kecanduan (Faggiano et al., 2008). Pencegahan ini perlu dilakukan karena pemain game online mungkin tidak menyadari potensi konsekuensi negatif dari game online sehingga membuatnya menjadi pecandu game online (Irmak \& Erdoğan, 2015).

Pencegahan yang dilakukan di sekolah menjadi penting karena remaja juga memiliki peran sebagai siswa dan waktunya banyak dihabiskan di sekolah. Upaya yang dilakukan sekolah lebih efisien karena dapat mencakup banyak siswa (Griffin \& Botvin, 2010). Selain itu, pencegahan yang dilakukan sekolah juga efektif (Wells et al., 2003). Keberhasilan pencegahan yang dilakukan sekolah terhadap penyalahgunaan narkoba (Faggiano et al., 2008) dan perjudian (Dickson et al., 2004) dapat memperkuat upaya pencegahan kecanduan game online.

Sekolah sebagai sarana pendidikan dapat memberikan upaya pencegahan kecanduan game online pada siswa (Throuvala et al., 2018). Hal ini bisa dilakukan dengan usaha meningkatkan pemahaman siswa tentang bahaya kecanduan game online. Menurut Irmak \& Erdoğan (2015)kurangnya pengetahuan dan pemahaman tentang bahaya game online mengakibatkan siswa bisa menjadi kecanduan. Maka upaya untuk meningkatkan pemahaman siswa tentang bahaya kecanduan game online menjadi sangat penting untuk dilakukan. Dibutuhkan peran nyata dari tenaga pendidik di sekolah untuk dapat membantu siswa memperoleh pemahaman tentang bahaya kecanduan game online agar dapat terhindar dari kecanduan game online. Salah satu tenaga pendidik yang dimaksud adalah guru BK.

Guru BK memiliki tugas untuk memberikan pelayanan kepada siswa. Pelayanan konseling dapat dimaknai sebagai model teoretis untuk membantu individu membuat keputusan hidup (Gladding, 2012). Fokus pelayanan BK kepada siswa ialah untuk melakukan pencegahan dan intervensi terhadap masalah perkembangan, gangguan dalam pendidikan, urusan pribadi, sosial, dan karier (Henderson \& Thompson, 2011). Salah satu fungsi pelayanan BK adalah mencegah terjadinya perilaku buruk siswa (Ahmad, 2017; Carlson \& Kees, 2013). Dalam hal ini guru BK harus mampu meluaskan jangkauan aktivitas pencegahan agar mampu mengidentifikasi dan mengintervensi populasi yang lebih besar yang berisiko mengalami gangguan (Gibson \& Mitchell, 2010). Untuk melakukan hal tersebut guru BK dapat memberikan layanan kepada seluruh siswa ataupun melakukan pengaturan kelompok besar. Apabila dibutuhkan guru BK dapat melakukan pengaturan kelompok kecil atau fokus terhadap siswa-siswa tertentu.

Banyak cara yang bisa dilakukan guru BK untuk meningkatkan pemahaman siswa tentang bahaya kecanduan game online antara lain dengan mengadakan sosialisasi dan seminar tentang dampak negatif kecanduan game online. Selain itu, guru BK dapat membuat modul tentang bahaya kecanduan game online. Selanjutnya, modul tersebut dapat membuat siswa lebih aktif dan mandiri dalam memahami informasi untuk meningkatkan pemahamannya tentang bahaya kecanduan game online. Berbagai upaya ini mesti dimasukkan ke dalam program BK agar terintegrasi dengan kurikulum.

Dalam upaya pencegahan terhadap kecanduan game online penting bagi guru BK untuk melibatkan orangtua siswa. Guru BK dan orangtua siswa harus dapat mengingatkan dan memberikan awareness kepada siswa tentang efek serius dari kecanduan game online. Terkhusus bagi orangtua, seharusnya dapat memperhatikan dan mengawasi kegiatan anaknya yang bisa saja menimbulkan bahaya. Hal ini penting dilakukan karena orangtua siswa memiliki kesempatan untuk mengasuh dan membentuk gaya hidup sehat bagi anaknya (Gibson \& Mitchell, 2010).

Berdasarkan penjelasan tersebut, dapat disimpulkan bahwa kecanduan game online perlu mendapat tindakan tegas sebagai langkah pencegahan. Salah satu langkah pencegahan yang dapat dilakukan yaitu 
dengan berusaha meningkatkan pemahaman siswa tentang bahaya kecanduan game online. Guru BK memegang peranan penting dalam usaha meningkatkan pemahaman siswa tentang bahaya kecanduan game online karena salah satu tugasnya adalah mencegah terjadinya perilaku buruk siswa. Adapun cara yang dapat dilakukan oleh guru BK, yaitu dengan memberikan sosialisasi, seminar dan modul tentang bahaya kecanduan game online serta melibatkan orangtua siswa dalam upaya pencegahan kecanduan game online.

\section{Kesimpulan}

Kecanduan game online akan berakibat buruk terhadap berbagai aspek kehidupan remaja. Remaja yang semestinya tumbuh dan berkembang dari berbagai aspek malah mengalami gangguan akibat kecanduan game online. Untuk itu, game online sebagai bentuk dari perkembangan teknologi perlu disikapi dengan bijak supaya tidak berdampak buruk bagi remaja. Guru BK harus melakukan upaya pencegahan salah satunya melalui peningkatan kemampuan kognitif siswa yaitu dengan memberikan pemahaman mengenai bahaya kecanduan game online. Pihak sekolah harus memberikan keleluasaan kepada guru BK mengadakan seminar dan sosialisai tentang game online dan bahayanya kepada orangtua dan siswa. Selain itu, guru BK dapat membuat modul tentang bahaya kecanduan game online dan memberikannya kepada siswa. Dengan demikian, diharapkan pemahaman siswa meningkat sehingga dapat terhindar dari kecanduan game online.

\section{Referensi}

Afdal, A., Alizamar, A., Ifdil, I., Ardi, Z., Sukmawati, I., Zikra, Z., Ilyas, A., Fikri, M., Syahputra, Y., \& Hariyani, H. (2019). An analysis of phubbing behaviour: Preliminary research from counseling perspective. Proceeding of 1st International Conference on Educational Sciences and Teacher Profession (ICETeP), 270-273. https://doi.org/10.2991/icetep-18.2019.65

Ahmad, R. (2017). Teacher guidance and counseling efforts to prevent cheating behavior. Proceeding of 9th International Conference for Science Educators and Teachers (ICSET), 765-770. https://doi.org/10.2991/icset-17.2017.126

Anggarani, F. K. (2015). Internet gaming disorder : Psikopatologi budaya modern. Buletin Psikologi, 23(1), 112. https://doi.org/10.22146/bpsi.10572

Brand, M., Young, K. S., Laier, C., Wölfling, K., \& Potenza, M. N. (2016). Integrating psychological and neurobiological considerations regarding the development and maintenance of specific internet-use disorders: An Interaction of Person-Affect-Cognition-Execution (I-PACE) model. Neuroscience and Biobehavioral Reviews, 71, 252-266. https://doi.org/10.1016/j.neubiorev.2016.08.033

Carlson, L. A., \& Kees, N. L. (2013). Mental health services in public schools: A preliminary study of school counselor perceptions. Professional School Counseling, 16(4), 211-221.

Cheever, N. A., Rosen, L. D., Carrier, L. M., \& Chavez, A. (2014). Out of sight is not out of mind: The impact of restricting wireless mobile device use on anxiety levels among low, moderate and high users. Computers in Human Behavior, 37, 290-297. https://doi.org/10.1016/j.chb.2014.05.002

Choo, H., Gentile, D. A., Sim, T., Li, D., Khoo, A., \& Liau, A. K. (2010). Pathological video-gaming among Singaporean youth. Annals of the Academy of Medicine, 39(11), 822-829.

Dickson, L. M., Derevensky, J. L., \& Gupta, R. (2004). Harm reduction for the prevention of youth gambling problems: Lessons learned from adolescent high-risk behavior prevention programs. Journal of Adolescent Research, 19(2), 233-263. https://doi.org/10.1177/0743558403258272

Dong, G., \& Potenza, M. N. (2014). A cognitive-behavioral model of Internet gaming disorder: Theoretical underpinnings and clinical implications. Journal of Psychiatric Research, 58, 7-11. https://doi.org/10.1002/cncr.27633.Percutaneous

Ducheneaut, N., \& Moore, R. J. (2004). The social side of gaming: A study of interaction patterns in a massively multiplayer online game. Proceeding of the ACM Conference on Computer-Supported Cooperative Work, 360-369.

Faggiano, F., Vigna-Taglianti, F. D., Versino, E., Zambon, A., Borraccino, A., \& Lemma, P. (2008). School-based prevention for illicit drugs' use: A systematic review. Preventive Medicine, 46(5), 385-396. https://doi.org/10.1002/14651858.cd003020.pub2

Gentile, D. A. (2009). Pathological video game use among youth ages 8 to 18: A national study. Psychological Science, 20(5), 594-603.

Ghuman, D., \& Griffiths, M. D. (2012). A cross-genre study of online gaming: Player demographics, motivation for play and social interactions among players. International Journal of Cyber Behavior, 
Psychology and Learning, 2(1), 13-29.

Gibson, R. L., \& Mitchell, M. H. (2010). Bimbingan dan konseling (Edisi Ketujuh) (Alih Bahasa Yudi Santoso). Pustaka Pelajar.

Gladding, S. T. (2012). Konseling profesi yang menyeluruh (Edisi Keenam) (Alih Bahasa P.M. Winarno dan Lilian Yuwono). Indeks.

Griffin, K. W., \& Botvin, G. J. (2010). Evidence-based intervention for preventing substance use disorders in adolescents. Child and Adolescent Psychiatric Clinics, 19(3), 505-526. https://doi.org/10.1016/j.chc.2010.03.005.Evidence-Based

Griffiths, M. D. (2017). The psychosocial impact of professional gambling, professional video gaming \& eSports. Casino \& Gaming International, 28, 59-63.

Griffiths, M. D., Davies, M. N. O., \& Chappell, D. (2004). Online computer gaming: A comparison of adolescent and adult gamers. Journal of Adolescence, 27(1), 87-96. https://doi.org/10.1016/j.adolescence.2003.10.007

Griffiths, M. D., Kuss, D. J., \& Pontes, H. M. (2016). A brief overview of internet gaming disorder and its treatment. Australian Clinical Psychologist, 2(1), 1-12.

Grizzard, M., Tamborini, R., Lewis, R. J., Wang, L., \& Prabhu, S. (2014). Being bad in a video game can make us morally sensitive. Cyberpsychology, Behavior and Social Networking, 17(8), 499-504. https://doi.org/10.1089/cyber.2013.0658

Hamari, J., \& Sjöblom, M. (2017). What is esport and why to people watch it? Internet Research, 27(2), 211232.

Han, D. H., Hwang, J. W., \& Renshaw, P. F. (2010). Bupropion sustained release treatment decreases craving for video games and cue-induced brain activity in patients with internet video game addiction. Experimental and Cinical Psychopharmacology, 18(4), 297-304. https://doi.org/10.1037/a0020023

Hanika, I. M. (2015). Fenomena phubbing di era milenia (ketergantungan seseorang pada smartphone terhadap lingkungannya). Interaksi: Jurnal Ilmu Komunikasi, 4(1), 42-51.

Henderson, D. A., \& Thompson, C. L. (2011). Counseling children (8th ed.). Brooks/Cole.

Hughes, M., \& Louw, J. (2013). Playing games: The salience of social cues and group norms in eliciting aggressive behaviour. South African Journal of Psychology, 43(2), 252-262. https://doi.org/10.1177/0081246313482629

Hurlock, E. B. (2010). Psikologi Perkembangan: Suatu Pendekatan Sepanjang Rentang Kehidupan (Edisi Kelima) (Alih Bahasa Istiwidayanti dan Soedjarwo). Erlangga.

Hussain, Z., \& Griffiths, M. D. (2009). Excessive use of massively multi-player online role-playing games: A pilot study. International Journal of Mental Health and Addiction, 7(2), 563-571. https://doi.org/10.1007/s11469-009-9202-8

Irmak, A. Y., \& Erdoğan, S. (2015). Digital game addiction among adolescents and younger adults: A current overview. Turkish Journal of Psychiatry, 27(2), 1-10.

Jannah, N., Mudjiran, M., \& Nirwana, H. (2015). Hubungan kecanduan game dengan motivasi belajar siswa dan implikasinya terhadap Bimbingan dan Konseling. Konselor, 4(4), $200-207$. https://doi.org/10.24036/02015446473-0-00

Jap, T., Tiatri, S., Jaya, E. S., \& Suteja, M. S. (2013). The development of Indonesian online game addiction questionnaire. PLOS ONE, 8(4), 4-8. https://doi.org/10.1371/journal.pone.0061098

Karadağ, E., Tosuntaş, Ş. B., Erzen, E., Duru, P., Bostan, N., Şahin, B. M., Çulha, I., \& Babadağ, B. (2015). Determinants of phubbing, which is the sum of many virtual addictions: A structural equation model. Journal of Behavioral Addictions, 4(2), 60-74. https://doi.org/10.1556/2006.4.2015.005

King, D. L., Delfabbro, P. H., Wu, A. M. S., Doh, Y. Y., Kuss, D. J., Pallesen, S., Mentzoni, R., Carragher, N., \& Sakuma, H. (2017). Treatment of internet gaming disorder: An international systematic review and CONSORT evaluation. Clinical Psychology Review, 54, 123-133.

Koo, C., Wati, Y., Lee, C. C., \& Oh, H. Y. (2011). Internet-addicted kids and South Korean government efforts: Boot-camp case. Cyberpsychology, Behavior and Social Networking, 14(6), 391-394.

Lam, L. T., \& Peng, Z. W. (2010). Effect of pathological use of the internet on adolescent mental health: A prospective study. Archives of Pediatrics \& Adolescent Medicine, 164(10), 901-906. https://doi.org/10.1001/archpediatrics.2010.159

Lemola, S., Brand, S., Vogler, N., Perkinson-Gloor, N., Allemand, M., \& Grob, A. (2011). Habitual computer game playing at night is related to depressive symptoms. Personality and Individual Differences, 51(2), 117-122. https://doi.org/10.1016/j.paid.2011.03.024

O’Connell, M. E., Boat, T., \& Warner, K. E. (2009). Preventing mental, emotional and behavioral disorders among 
young people: Progress and possibilities. The National Academies Press.

Pallesen, S., Lorvik, I. M., Bu, E. H., \& Molde, H. (2015). An exploratory study investigating the effects of a treatment manual for video game addiction. Psychological Reports: Mental \& Pshysical Health, 117(2), 490495. https://doi.org/10.2466/02.PR0.117c14z9

Park, Y., \& Chen, J. C. V. (2007). In search of factors to online game addiction and its implications. Journal of International Technology and Information Management, 16(2), 73-80.

Petrides, K. V., \& Furnham, A. (2000). On the dimensional structure of emotional intelligence. Personality and Individual Differences, 29(2), 313-320.

Prayitno, E. (2006). Psikologi perkembangan remaja. Angkasa Raya.

Rehbein, F., Kliem, S., Baier, D., Mößle, T., \& Petry, N. M. (2015). Prevalence of internet gaming disorder in German adolescents: Diagnostic contribution of the nine DSM-5 criteria in a state-wide representative sample. Addiction, 110(5), 842-851. https://doi.org/10.1111/add.12849

Romano, J. L., \& Hage, S. M. (2000). Prevention and counseling psychology: Revitalizing commitments for the 21st century. The Counseling Psychologist, 28(6), 733-763.

Romano, J. L., \& Netland, J. D. (2008). The application of the theory of reasoned action and planned behavior to counseling psychology. The Counseling Psychologist, 36(5), 777-806.

Rutter, H., Savona, N., Glonti, K., Bibby, J., Cummins, S., Finegood, D. T., Greaves, F., Harper, L., Hawe, P., Moore, L., Petticrew, M., Rehfuess, E., Shiell, A., Thomas, J., \& White, M. (2017). The need for a complex systems model of evidence for public health. The Lancet, 390(10112), 2602-2604. https://doi.org/10.1016/S0140-6736(17)31267-9

Sanderi, F., Marjohan, M., \& Sukmawati, I. . (2013). Kepatuhan siswa terhadap disiplin dan upaya guru BK dalam meningkatkannya melalui layanan informasi. Konselor, 2(1), $220-224$. https://doi.org/10.24036/02013211008-0-00

Stone, C., \& Dahir, C. A. (2015). The transformed school counselor (3rd ed.). Cengage Learning.

Syahran, R. (2015). Ketergantungan online game dan penanganannya. Jurnal Psikologi Pendidikan Dan Konseling, 1(1), 84-92. https://doi.org/10.26858/jpkk.v1i1.1537

Taylor, T. L. (2006). Play between worlds: Exploring online gaming culture. The MIT Press.

Throuvala, M. A., Griffiths, M. D., Rennoldson, M., \& Kuss, D. J. (2018). School-based prevention for adolescent internet addiction: Prevention is the key. A systematic literature review. Current Neuropharmacology, 17(6), 507-525. https://doi.org/10.2174/1570159x16666180813153806

van Rooij, A. J., Schoenmakers, T. M., Vermulst, A. A., van den Eijnden, R. J. J. M., \& van de Mheen, D. (2011). Online video game addiction: Identification of addicted adolescent gamers. Addiction, 106(1), 205-212. https://doi.org/10.1111/j.1360-0443.2010.03104.x

Wangid, M. N. (2010). Peran konselor sekolah dalam pendidikan karakter. Cakrawala Pendidikan, 3(1), 173186.

Weiss, T. (2011). Fulfilling the needs of eSports consumers: A uses and gratifications perspective. Proceedings of 24th Bled eConference, 572-580.

Wells, J., Barlow, J., \& Stewart-Brown, S. (2003). A systematic review of universal approaches to mental health promotion in schools. Health Education, 103(4), 197-220. https://doi.org/10.1108/09654280310485546

Xu, Z., Turel, O., \& Yuan, Y. (2012). Online game addiction among adolescents: Motivation and prevention factors. European Journal of Information Systems, 21(3), 321-340. https://doi.org/10.1057/ejis.2011.56

Young, K. S. (2011). CBT-IA: The first treatment model for internet addiction. Journal of Cognitive Psychotherapy, 25(4), 304-312. https://doi.org/10.1891/0889-8391.25.4.304

Zamroni, E., \& Rahardjo, S. (2015). Manajemen Bimbingan dan Konseling berbasis Permendikbud Nomor 111 tahun 2014. Jurnal Konseling Gusjigang, 1(1), 1-11. https://doi.org/10.24176/jkg.v1i1.256

Zhou, Z., Yuan, G., \& Yao, J. (2012). Cognitive biases toward internet game-related pictures and executive deficits in individuals with an internet game addiction. PLoS ONE, 7(11), e48961. https://doi.org/10.1371/journal.pone.0048961 